\title{
AEROMAGNETIC MAP OF THE SHARON QUADRANGLE AND PARTS OF THE ELLSWORTH AND BASHBISH FALLS QUADRANGLES, CONNECTICUT AND NEW YORK
}

\author{
GEOPHYSICAL INVESTIGATIONS \\ MÃP GP-640
}

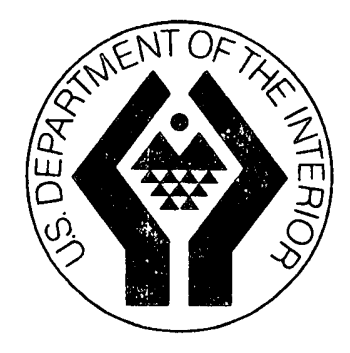

